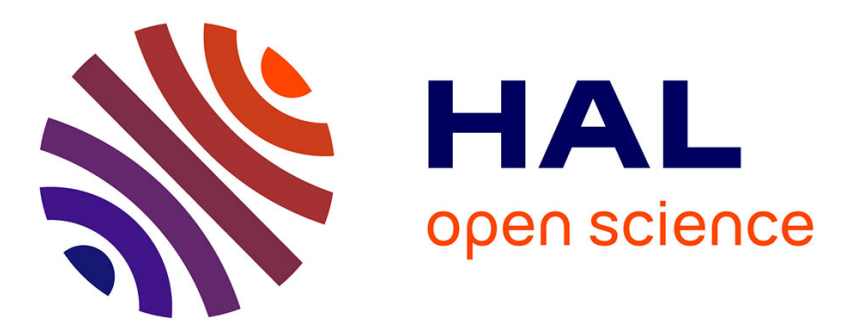

\title{
Analysis of Optimizers to Regulate Occupant's Actions for Building Energy Management
}

Monalisa Pal, Raunak Sengupta, Sanghamitra Bandyopadhyay, Amr Alzouhri Alyafi, Stéphane Ploix, Patrick Reignier, Sriparna Saha

\section{- To cite this version:}

Monalisa Pal, Raunak Sengupta, Sanghamitra Bandyopadhyay, Amr Alzouhri Alyafi, Stéphane Ploix, et al.. Analysis of Optimizers to Regulate Occupant's Actions for Building Energy Management. ICAPR 2017 - Ninth International Conference on Advances in Pattern Recognition, Dec 2017, Bangalore, India. https://ieexplore.ieee.org/document/8593024. hal-01675162

\section{HAL Id: hal-01675162 \\ https://hal.science/hal-01675162}

Submitted on 4 Jan 2018

HAL is a multi-disciplinary open access archive for the deposit and dissemination of scientific research documents, whether they are published or not. The documents may come from teaching and research institutions in France or abroad, or from public or private research centers.
L'archive ouverte pluridisciplinaire HAL, est destinée au dépôt et à la diffusion de documents scientifiques de niveau recherche, publiés ou non, émanant des établissements d'enseignement et de recherche français ou étrangers, des laboratoires publics ou privés. 


\title{
Analysis of Optimizers to Regulate Occupant's Actions for Building Energy Management
}

\author{
Monalisa Pal ${ }^{1 \star}$, Raunak Sengupta ${ }^{2}$, Sanghamitra Bandyopadhyay ${ }^{1}, \mathrm{Amr}$ \\ Alzouhri Alyafi ${ }^{3,4}$, Stéphane Ploix ${ }^{3}$, Patrick Reignier ${ }^{5}$, and Sriparna Saha ${ }^{6}$ \\ 1 Machine Intelligence Unit, Indian Statistical Institute, Kolkata, India \\ 2 Department of Electrical Engineering, Indian Institute of Technology Patna, India \\ ${ }^{3}$ GSCOP Laboratory, Grenoble Institute of Technology, Grenoble, France \\ 4 LIG Laboratory, Grenoble Institute of Technology, Grenoble, France \\ 5 Univ. Grenoble Alpes, CNRS, INRIA, LIG, F-38000 Grenoble, France \\ ${ }^{6}$ Department of Computer Science and Technology, Indian Institute of Technology \\ Patna, India \\ monalisap90@gmail.com, raunaksengupta@gmail.com, \\ sanghami@gmail.com, amr.alzouhri-alyafi@imag.fr, \\ stephane.ploix@grenoble-inp.fr, patrick.reignier@inria.fr, \\ sriparna.saha@gmail.com
}

\begin{abstract}
Occupants and their actions play major roles in building energy management as reported by previous studies, which involves finding the optimal schedule of user actions, under a given physical context, in order to minimize their dissatisfaction. However, comparison and performance analysis of various optimizers, for the concerned problem, have not been studied previously, which is essential to gain insight into the underlying characteristics of the problem. In this work, the performance of four popular and contemporary multi-objective optimization algorithms viz. DEMO, NSGA-II, NSGA-III, and $\theta$-DEA, for estimating the optimal schedule has been analyzed in terms of their abilities to find minimal average indoor conditions, to discover more number of alternative trade-off solutions (flexibility) and to promptly converge to a smaller minimal net dissatisfaction value (speed of convergence). Results show that NSGA-II has slightly better capabilities than NSGA-III and $\theta$-DEA, but it clearly outperforms DEMO. The recently developed population dynamics indicators are also applied to support the observed features of the optimizers. The proposed analyzing paradigm can also be used when the optimization problem is extended to include several other objectives.
\end{abstract}

\section{Introduction}

Energy management in buildings is an essential concern as a majority (as much as $40 \%$ ) of the global energy is consumed by buildings $[8,9,1]$. The primary goal of this energy management is to improve the comfort of occupants without increasing the energy consumption. On one hand, the depletion in natural resource

\footnotetext{
* corresponding author.
} 
bank at an alarming rate and, on the other hand, the ever-growing demand of the inhabitants, is at the cross-roads which is demanding the research community for developing intelligent energy regulation strategies. Recently, it came to light that there is a considerable impact of actions of occupants on the building energy management $[1,9]$. Thus, it is imperative to analyze and propose actions, given a physical context, such that dissatisfaction of the occupants could be minimized without increasing the energy input.

Building energy management has been studied over two decades. Studies $[1,10]$ show that the inhabitants can reduce their thermal and/or air quality dissatisfaction (using Differential Evolution for Multi-objective Optimization (DEMO)) by following a proposed optimal schedule of actions (opening and closing of doors and windows). However, besides regulating user actions, other energy managing devices like HVAC (Heating, Ventilation and Air Conditioning) system is needed to reduce dissatisfaction when the outdoor temperature is much higher than the preferred range of temperature [10]. The impact of occupant's actions is studied by relating the degree of changes between actions (cause) and comfort (effect) [1] which helps the occupants to prioritize the necessary changes in their schedule. Analysis of energy consumption during both occupied and nonoccupied hours shows that changes in occupant's actions can help in limiting this excess energy consumption [9]. Variation in the amount of coordination between energy managing devices and occupants can address multiple levels of comfort ranges and occupancies [8]. While some studies $[8,9]$ consider both devices and occupants as energy controlling agents, others $[10,1]$ concentrate only on the role of occupants. The work presented in this manuscript primarily focuses on two aspects: solely on the impact from user actions and analysis of the optimization for building energy management.

For the first time in this application, the optimization performance of DEMO is compared with other popular and/or contemporary multi-objective optimization algorithms viz. Non-dominated Sorting Genetic Algorithm or NSGA-II [4], NSGA-III [5] and $\theta$-Dominance based Evolutionary Algorithm or $\theta$-DEA [14]. The comparison is made in terms of their ability to minimize the indoor temperature and $\mathrm{CO}_{2}$ concentration, flexibility to find higher number of trade-off solutions such that the users have more alternatives and the speed of convergence. Moreover, the recently developed population dynamics indicators [13] are also applied to summarize the population movement such that the features of the underlying landscape of the problem and the ability of the optimizers to deal with these features could be analyzed.

In the rest of the paper, the experimental details are outlined in Section 2, the essential observations are noted in Section 3, and the paper is concluded in Section 4 with future directions.

\section{Experimental Paradigm}

This energy management problem proposes schedules of actions to the building occupants in order to minimize their dissatisfaction. The dissatisfaction depends 
on the variations in occupant's actions (like opening/closing of doors/windows) and on environmental factors (like outside temperature and $\mathrm{CO}_{2}$ concentration, wind speed, solar radiation, etc.). The experiment involves simulating indoor conditions (temperature and $\mathrm{CO}_{2}$ concentration) based on random actions and recorded environmental factors, and searching for the actions that can lead to more comfortable indoor conditions when similar environmental factors appear. For simulation, a physical model [1] is used, which embeds structural information like thermal resistance of walls and door $(R)$, volume of room $(V)$, thermal coefficient of building inertia $(\tau)$, breath $\mathrm{CO}_{2}$ production $\left(S_{\mathrm{CO}_{2}}\right)$, etc. These experimental steps are shown in Fig. 1.

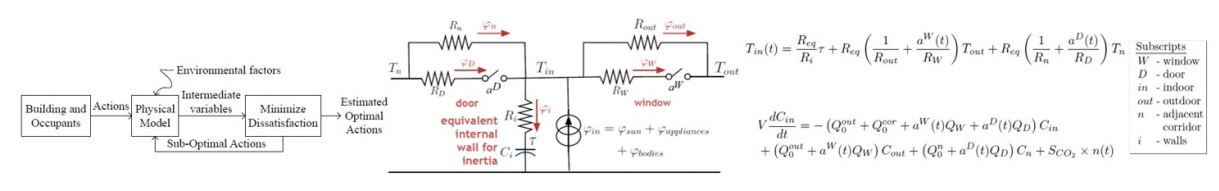

Fig. 1. Experimental Framework and the Physical Model

\subsection{Details of Testbed}

The experimental database from $[10,1]$ is utilized where data is recorded over 100 days (April 1, 2015 to July 9, 2015, 8am to 8pm) from a research office at Grenoble Institute of Technology, France, which is fitted with 27 sensors (HVAC system absent) and where four researchers work. Some of the sensors measure temperature $(T)$, air speed $(Q)$, heat flow $(\varphi)$, solar illuminance, $\mathrm{CO}_{2}$ concentration $(C)$, moisture, etc. while the other sensors detect motions, measure acoustic pressure, power consumption, etc. to estimate the number of occupants $(n(t))$ at a time-instant $[3,2]$. For performance analysis, the entire period is divided into 10 groups (Group 1 to Group 10), each of 10 days, as done in [10]. This database has a two-fold purpose:

- To assist in tuning of the physical model to match simulated indoor conditions with recorded indoor conditions by rerunning recorded actions from the database

- To generate indoor conditions, corresponding to hypothetical schedules of actions, in order to quantify the dissatisfaction of the occupant, during optimization

\subsection{Optimization Problem Formulation}

The mathematical formulation of the underlying optimization problem $[1,10]$ is given by Eq. (1) where $A$ represents the set of actions, $D_{t h}^{k}$ and $D_{\text {air }}^{k}$ represents the average thermal and air quality dissatisfaction at the $k$-th hour, respectively. 


$$
\text { Minimize: } D(A)=\left[\frac{\sum_{k=1}^{12} D_{t h}^{k}(A)}{12}, \frac{\sum_{k=1}^{12} D_{a i r}^{k}(A)}{12}\right]
$$

Representation of Candidate Solution In absence of HVAC system, the only controllable parameters that can influence the indoor conditions are the actions (opening/closing of doors/windows) of the occupants. Thus, the solution vector of the optimization problem is encoded as a 24 -dimensional binary vector as shown in Fig. 2, where its elements are the status of door/window at every hour (from 8 am to $8 \mathrm{pm}$ ).

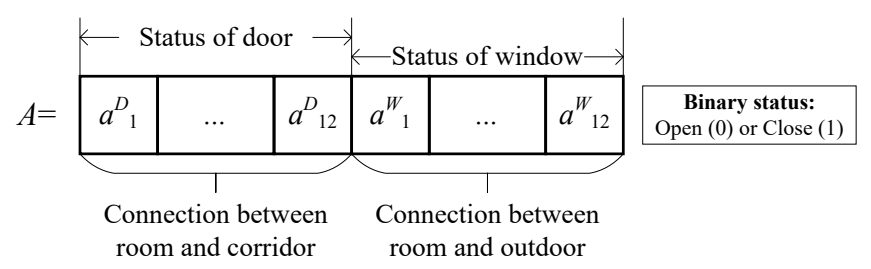

Fig. 2. Candidate Solution of the Optimization Problem

Optimization Objectives The algorithm searches for optimal actions such that thermal dissatisfaction (Eq. (2)) and $\mathrm{CO}_{2}$ based air quality dissatisfaction (Eq. (3)) are minimized. These criteria are dependent on indoor temperature $\left(T_{i n}^{k}\right.$ in $\left.{ }^{\circ} \mathrm{C}\right)$ and indoor $\mathrm{CO}_{2}$ concentration $\left(C_{i n}^{k}\right.$ in ppm) at the $k$-th hour which are, in turn, dependent on the schedule of occupant's actions $(A)$ as shown by the physical model $[1,10]$ in Fig. 1.

$$
\begin{aligned}
& D_{t h}^{k}\left(T_{i n}^{k}\right)= \begin{cases}\frac{21-T_{i n}^{k}}{21-18} & , \text { if } T_{i n}^{k}<21 \\
0 & , \text { if } 21 \leq T_{i n}^{k} \leq 23 \\
\frac{T_{i n}^{k}-23}{26-23} & , \text { if } T_{i n}^{k}>23\end{cases} \\
& D_{a i r}^{k}\left(C_{i n}^{k}\right)= \begin{cases}0 & , \text { if } C_{i n}^{k} \leq 400 \\
\frac{C_{i n}^{k}-400}{1500-400} & , \text { if } C_{i n}^{k}>400\end{cases}
\end{aligned}
$$

When outdoor temperature is moderately high, opening windows can lead to increase in $T_{i n}$ and $C_{i n}$, thereby improving $D_{t h}$ while deteriorating $D_{a i r}$. Such situations lead to the conflicting nature of the objectives and thus, presents a multi-objective optimization (MOO) problem.

Stopping Criteria The optimization procedure is terminated after a maximum of 300 iterations $\left(I^{\max }=300\right)$. However, to avoid delay, if the minimum distance of a solution from ideal solution (no dissatisfaction) changes by less than $10^{-5}$ over 10 iterations, the optimization is terminated. 


\subsection{Significant Pareto-optimal Solutions}

For this work, Pareto-optimality [1] is the state where thermal dissatisfaction cannot be decreased unless air quality based dissatisfaction is increased or viceversa. Thus, the optimization algorithm results in a Pareto-optimal set (solution set/schedules of actions in decision space) and the Pareto-front (objectives/dissatisfaction corresponding to the Pareto-optimal set). The occupants, based on their preference, is allowed to choose one of the solutions as their preferred optimal schedule of actions. For further investigation, the schedules for the following points of the Pareto-front $(P F)$ are analysed:

- Minimal average $D_{t h}$ : At the boundary of $P F$

- Minimal average $D_{\text {air }}$ : At the boundary of $P F$

- Equally best compromise: Point having minimum net dissatisfaction $\left(D^{\star}\right.$ : $\left.\min \left(D_{t h}+D_{\text {air }}\right)\right)$ value

\section{$3 \quad$ Results and Discussions}

The proposed approach has been implemented in a Computer with 8GB RAM having an Intel Core i7 processor @ 2.20 GHz running Python 3.4. Four stateof-the-art MOO algorithms viz. DEMO [1,10,12], NSGA-II [4], NSGA-III [5] and $\theta$-DEA [14], have been used for the experiment and the results obtained are compared with each other to report the best optimization algorithm under a given preference. For each of the algorithms, the median values of the results are noted as obtained over the 50 executions. All the parameters of DEMO have been set as specified in $[1,10]$. Since the candidate solution is a binary sequence, single point crossover and binary mutation have been used for NSGA-II, NSGAIII and $\theta$-DEA. The crossover point is chosen randomly at every iteration and the mutation probability is set at a value of $1 / 24$ i.e. the inverse of the length of a candidate solution.

\subsection{Recommended Optimizers for Optimal Comfort}

From the different alternatives in the PF as presented to the occupant, a schedule is chosen using which the physical model simulates the indoor conditions. It should be noted that due to the inertia present in the physical variables, $T_{i n}^{k}$ and $C_{i n}^{k}$ are not only dependent on the actions at the $k$-th hour [1] but also on the initial indoor conditions and all the actions up to the $k$-th hour. Thus, the plots of average $T_{i n}^{k}$ (and $C_{i n}^{k}$ ) against time resulting from a schedule are crucial for decision making. Examples of such plots are shown in Fig. 3 for an experimental day (April 20, 2015) where difference is observed in the last two hours $(6-8 \mathrm{pm})$. The minimum average area under the step curve, which indicates the average temperature or $\mathrm{CO}_{2}$ concentration for the entire day, is considered as an indicator of the best optimizer. Based on this indicator, the best optimizer is noted in Table 1. Due to lack of space, results corresponding to only one day from each of the 10 groups are mentioned in this paper. 


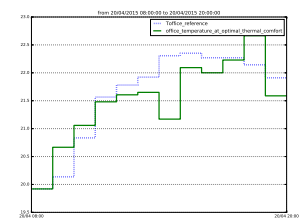

(a) with DEMO

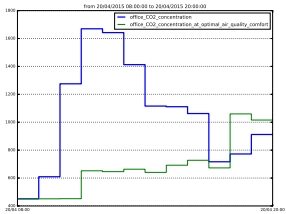

(e) with DEMO

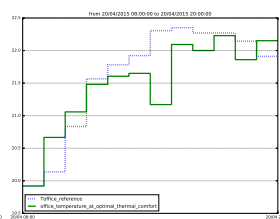

(b) with NSGA-II

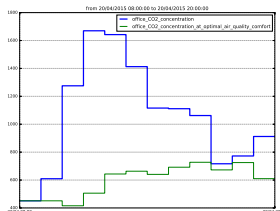

(f) with NSGA-II

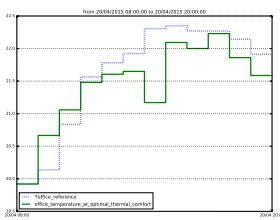

(c) with NSGA-III

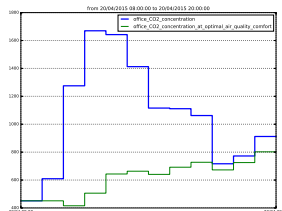

(g) with NSGA-III

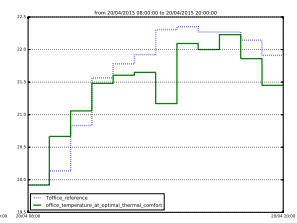

(d) with $\theta$-DEA

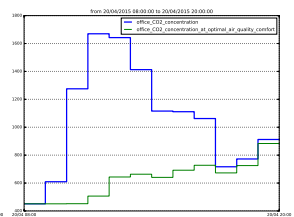

(h) with $\theta$-DEA

Fig. 3. Variation of (a-d) Indoor Temperature $\left(T_{i n}^{k}\right)$ and (e-h) Indoor $\mathrm{CO}_{2}$ concentration $\left(C_{i n}^{k}\right)$ against Time for Occupant's Usual Schedule (blue) as compared with Best Schedules (green) Corresponding to Minimal Thermal $\left(D_{t h}\right)$ and Air Quality $\left(D_{a i r}\right)$ Dissatisfaction

Table 1. Recommended Optimizers Based on Average Temperature and Average $\mathrm{CO}_{2}$ Concentration

\begin{tabular}{|c|c|c|c|c|}
\hline & \multicolumn{2}{|c|}{ Average Temperature $\left(\right.$ in $\left.{ }^{\circ} \mathrm{C}\right)$} & \multicolumn{2}{|c|}{ Average $\mathrm{CO}_{2}$ concentration (in ppm) } \\
\hline $\begin{array}{l}\text { Group } \\
\text { (Date) }\end{array}$ & $\begin{array}{l}\text { @ Minimal } D_{t h} \\
\text { (Best optimizer) }\end{array}$ & $\begin{array}{c}\text { @ Occupant's } \\
\text { Usual }\end{array}$ & $\begin{array}{l}\text { @ Minimal } D_{a i r} \\
\text { (Best optimizer) }\end{array}$ & $\begin{array}{c}\text { @ Occupant's } \\
\text { Usual }\end{array}$ \\
\hline $\begin{array}{c}1 \\
\text { (April 08) }\end{array}$ & $\begin{array}{c}20.9862 \\
\text { (DEMO) }\end{array}$ & 21.3120 & $\begin{array}{c}601.0635 \\
\text { (NSGA-II/NSGA-III) }\end{array}$ & 791.0627 \\
\hline $\begin{array}{c}2 \\
\text { (April 20) }\end{array}$ & $\begin{array}{c}21.4320 \\
(\theta-\mathrm{DEA})\end{array}$ & 21.6176 & $\begin{array}{c}599.9790 \\
\text { (NSGA-II) }\end{array}$ & 1062.6929 \\
\hline $\begin{array}{c}3 \\
\text { (April 27) }\end{array}$ & $\begin{array}{l}22.6554 \text { (NSGA-II/ } \\
\text { NSGA-III/ } \theta \text {-DEA) }\end{array}$ & 24.1531 & $\begin{array}{c}573.5144 \text { (NSGA-II/ } \\
\text { NSGA-III/ } \theta \text {-DEA) }\end{array}$ & 887.2458 \\
\hline $\begin{array}{c}4 \\
\text { (May 05) }\end{array}$ & $\begin{array}{c}23.358 \\
(\mathrm{NSGA}-\mathrm{III} / \theta-\mathrm{DEA})\end{array}$ & 23.9480 & $\begin{array}{c}542.0127 \\
(\text { NSGA-II/NSGA-III) }\end{array}$ & 807.3179 \\
\hline $\begin{array}{c}5 \\
(\text { May 20) }\end{array}$ & $\begin{array}{l}21.6399 \\
\text { (DEMO) }\end{array}$ & 23.2467 & $\begin{array}{l}573.8091 \\
\text { (DEMO) }\end{array}$ & 816.6128 \\
\hline $\begin{array}{c}6 \\
\text { (May 28) }\end{array}$ & $\begin{array}{c}22.0747 \\
\text { (NSGA-II/NSGA-III) }\end{array}$ & 22.5711 & $\begin{array}{c}474.4113 \text { (NSGA-II/ } \\
\text { NSGA-III/ } \theta \text {-DEA) }\end{array}$ & 605.4587 \\
\hline $\begin{array}{c}7 \\
\text { (June 05) }\end{array}$ & $\begin{array}{c}27.054 \\
\text { (NSGA-III) }\end{array}$ & 27.4792 & $\begin{array}{c}440.6978 \\
\text { (NSGA-II/NSGA-III) }\end{array}$ & 498.9001 \\
\hline $\begin{array}{c}8 \\
\text { (June 19) }\end{array}$ & $\begin{array}{c}24.9376 \\
(\theta-\mathrm{DEA})\end{array}$ & 25.6832 & $\begin{array}{c}453.6374 \\
(\text { NSGA-II) }\end{array}$ & 439.0857 \\
\hline $\begin{array}{c}9 \\
\text { (June 23) }\end{array}$ & $\begin{array}{c}25.1341 \\
\text { (NSGA-III) }\end{array}$ & 25.7144 & $\begin{array}{c}447.6200 \\
\text { (NSGA-III) }\end{array}$ & 441.4343 \\
\hline $\begin{array}{c}10 \\
\text { (July 01) }\end{array}$ & $\begin{array}{c}29.2638 \\
\text { (NSGA-II/NSGA-III) }\end{array}$ & 29.4705 & $\begin{array}{c}507.2125 \\
\text { (NSGA-III) }\end{array}$ & 459.1590 \\
\hline
\end{tabular}

It is observed from Table 1 that the minimum average indoor temperature has been attained by NSGA-III (in 6 out of 10 cases) whereas minimum average 
$\mathrm{CO}_{2}$ concentration is attained by NSGA-II (in 7 out of 10 cases). Thus, when the occupants are interested solely in minimizing either $D_{t h}$ or $D_{a i r}$, correspondingly NSGA-III or NSGA-II is the optimizer of choice. The superior performance for NSGA-II can be accounted to the use of crowding distance based ranking strategy which has a tendency to discover boundary points of the Pareto-front [7]. On the other hand, for NSGA-III, better exploration of the objective space depends on a good distribution of the reference lines which partition the objective space into multiple neighborhoods along which the optimization occurs. The reference lines are simple to set for this experiment as the objective space is two-dimensional. Here, the number of reference lines has been considered to be equal to the number of candidates in a population.

\subsection{Optimizer Discovering Majority of Pareto-front}

As the occupants are allowed to choose the schedule from the PF as per their preference, it is very important that the PF is densely sampled. After combining the non-dominated solution set from the four MOO algorithms and filtering out the dominated solutions, a non-dominated solution set is obtained whose constituent solutions are the result of one of the MOO algorithms. The proportion of this solution set discovered by a particular MOO algorithm indicates: (1) its ability to provide more options for the occupants, and (2) the convergence capability. These resulting fractions are mentioned in Table 2 for one of the experimental days in each of the group.

Table 2. Overall Fraction of Non-dominated Solutions Discovered by MOO Algorithms (Best Value in Boldface)

\begin{tabular}{|c|c|c|c|c|c|}
\hline Group & Date & DEMO & NSGA-II & NSGA-III & $\theta$-DEA \\
\hline 1 & April 08 & 0.1304 & $\mathbf{0 . 2 8 9 9}$ & $\mathbf{0 . 2 8 9 9}$ & $\mathbf{0 . 2 8 9 9}$ \\
\hline 2 & April 20 & 0.0000 & $\mathbf{0 . 3 3 3 3}$ & $\mathbf{0 . 3 3 3 3}$ & $\mathbf{0 . 3 3 3 3}$ \\
\hline 3 & April 27 & 0.0000 & $\mathbf{0 . 3 3 3 3}$ & $\mathbf{0 . 3 3 3 3}$ & $\mathbf{0 . 3 3 3 3}$ \\
\hline 4 & May 05 & 0.0000 & $\mathbf{0 . 3 3 3 3}$ & $\mathbf{0 . 3 3 3 3}$ & $\mathbf{0 . 3 3 3 3}$ \\
\hline 5 & May 20 & $\mathbf{0 . 2 5 0 0}$ & $\mathbf{0 . 2 5 0 0}$ & $\mathbf{0 . 2 5 0 0}$ & $\mathbf{0 . 2 5 0 0}$ \\
\hline 6 & May 28 & 0.0000 & $\mathbf{0 . 3 3 9 0}$ & $\mathbf{0 . 3 3 9 0}$ & 0.3220 \\
\hline 7 & June 05 & 0.0000 & $\mathbf{0 . 3 7 7 4}$ & 0.3585 & 0.2642 \\
\hline 8 & June 19 & $\mathbf{0 . 2 5 0 0}$ & $\mathbf{0 . 2 5 0 0}$ & $\mathbf{0 . 2 5 0 0}$ & $\mathbf{0 . 2 5 0 0}$ \\
\hline 9 & June 23 & $\mathbf{0 . 2 5 0 0}$ & $\mathbf{0 . 2 5 0 0}$ & $\mathbf{0 . 2 5 0 0}$ & $\mathbf{0 . 2 5 0 0}$ \\
\hline 10 & July 01 & $\mathbf{0 . 2 5 9 7}$ & 0.2208 & $\mathbf{0 . 2 5 9 7}$ & $\mathbf{0 . 2 5 9 7}$ \\
\hline \multicolumn{7}{|c|}{ Mean } & 0.1140 & 0.2977 & 0.2997 & 0.2886 \\
\hline Standard Deviation & 0.1256 & 0.0523 & 0.0441 & 0.0380 \\
\hline
\end{tabular}

It is observed from Table 2 that NSGA-II and NSGA-III have equal abilities to discover the solutions in the Pareto-front. The performance of $\theta$-DEA in this regard is also comparable. Moreover, the variation in the performance in terms of these fractions is very small for NSGA-II, NSGA-III and $\theta$-DEA which indicates steady performance. However, DEMO lies far behind the other MOO algorithms in its capability to discover much of the Pareto-front. This is because of the fact that DEMO performs ranking based on net dissatisfaction $[10,1]$ which is 


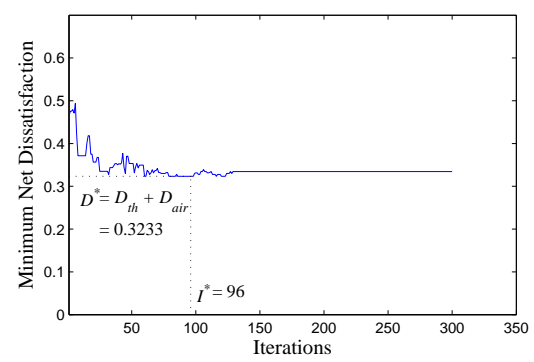

(a)

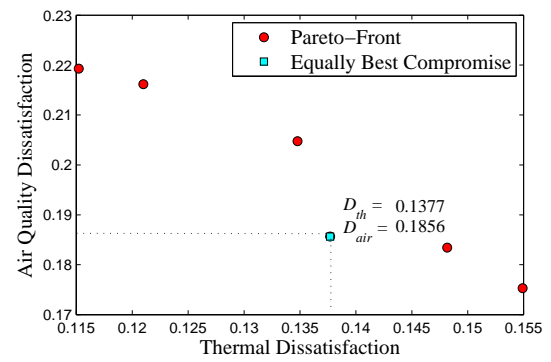

(b)

Fig. 4. Illustration of Parameters for Speed of Convergence and Minimal Net Dissatisfaction

strictly a convergence based ranking and hence, fails at preserving the diversity of solutions in the final solution set. On the other hand, NSGA-II [4], NSGA-III [5] and $\theta$-DEA [14] have their inherent diversity preserving mechanisms.

\subsection{Speed of Convergence and the Minimal Net Dissatisfaction}

Considering equal preference among both the objectives, net dissatisfaction is just the sum of thermal and air quality dissatisfaction. Occupant's preference, if any, could be incoporated using weighted sum. From multiple non-dominated solutions, the schedule corresponding minimum net dissatisfaction $\left(D^{\star}\right)$ is presented to the occupant as the equally best compromise among the objectives. A MOO algorithm which swiftly achieves the lowest value of $D^{\star}$ is preferred. However, solely targeting $D^{\star}$ (single objective) would be counter-productive as (1) diversity would be hampered, and (2) conflict among objectives would not be accounted.

Let $I^{\star}$ be the iteration by which $D^{\star}$ is reached and after which subsequent change in $D^{\star}$ over next 10 iterations is less than $10^{-5}$ (implying $D^{\star}$ is practically constant). The concept of $I^{\star}$ and $D^{\star}$ is demonstrated in Fig. 4 for an experimental day (April 08, 2015) from the results of DEMO. The ratio of $I^{\star}$ to $I^{\max }$ indicates the speed of convergence of a $\mathrm{MOO}$ algorithm. This ratio $\left(I^{\star}: I^{\max }\right)$ along with the corresponding value $D^{\star}$ is mentioned in Table 3 for one of the experimental days in each of the 10 groups.

It can be observed from Table 3 that the genetic algorithms (NSGA-II, NSGA-III) in general attain a better value of minimal net dissatisfaction as compared to differential evolution (DEMO). This can be attributed to the fact that the candidate solution is a binary sequence and NSGA-II, NSGA-III, and $\theta$-DEA use binary crossover and binary mutation operations, whereas, DEMO is inherently designed for continuous function optimization [12] and hence, does not act suited for this problem even after small modifications done in $[10,1]$.

NSGA-II is computationally faster per iteration as compared to NSGA-III and $\theta$-DEA although their orders are same. This can be accredited to the use of 
Table 3. Speed of Convergence to the Minimal Net Dissatisfaction by MOO Algorithms (Best Value in Boldface)

\begin{tabular}{|c|c|c|c|c|c|}
\hline \multicolumn{6}{|c|}{ Speed of Convergence $\left(I^{\star}: I^{\max }\right)$} \\
\hline Group & Date & DEMO & NSGA-II & NSGA-III & $\theta$-DEA \\
\hline 1 & April 08 & 0.3200 & 0.0533 & 0.1267 & 0.0900 \\
\hline 2 & April 20 & 0.1333 & 0.1033 & 0.1267 & 0.0800 \\
\hline 3 & April 27 & 0.8367 & 0.1300 & 0.1167 & 0.1000 \\
\hline 4 & May 05 & 0.3167 & 0.1333 & 0.0867 & 0.0867 \\
\hline 5 & May 20 & 0.1467 & 0.0700 & 0.0700 & 0.0733 \\
\hline 6 & May 28 & 0.1667 & 0.0867 & 0.1433 & 0.1333 \\
\hline 7 & June 05 & 0.4967 & 0.1033 & 0.0967 & 0.0467 \\
\hline 8 & June 19 & 0.0800 & 0.0800 & 0.0533 & 0.0867 \\
\hline 9 & June 23 & 0.0900 & 0.3967 & 0.5833 & 0.5267 \\
\hline 10 & July 01 & 0.2733 & 0.1000 & 0.1400 & 0.1000 \\
\hline \multicolumn{2}{|r|}{ Mean } & 0.2860 & 0.1257 & 0.1543 & 0.1323 \\
\hline Standa & rd Deviation & 0.2328 & 0.0984 & 0.1537 & 0.1403 \\
\hline \multicolumn{6}{|c|}{ Minimal Net Dissatisfaction $\left(D^{\star}\right)$} \\
\hline Group & Date & DEMO & NSGA-II & \multicolumn{2}{|c|}{\begin{tabular}{|l|l|} 
NSGA-III & $\theta$-DEA \\
\end{tabular}} \\
\hline 1 & April 08 & 0.3233 & 0.3233 & 0.3233 & 0.3233 \\
\hline 2 & April 20 & 0.2544 & 0.2254 & 0.2254 & 0.2254 \\
\hline 3 & April 27 & 0.2632 & 0.2627 & 0.2638 & 0.2632 \\
\hline 4 & May 05 & 0.3357 & 0.3114 & 0.3084 & 0.3084 \\
\hline 5 & May 20 & 0.1242 & 0.0813 & 0.0813 & 0.0813 \\
\hline 6 & May 28 & 0.1266 & 0.1221 & 0.1221 & 0.1221 \\
\hline 7 & June 05 & 1.6968 & 1.6555 & 1.6555 & 1.6557 \\
\hline 8 & June 19 & 0.6034 & 0.6034 & 0.6034 & 0.6034 \\
\hline 9 & June 23 & 0.6680 & 0.6680 & 0.6680 & 0.6680 \\
\hline 10 & July 01 & 2.1938 & 2.1938 & 2.1956 & 2.1972 \\
\hline \multicolumn{2}{|r|}{ Mean } & 0.6589 & 0.6447 & 0.6447 & 0.6448 \\
\hline \multicolumn{2}{|c|}{ Standard Deviation } & 0.7105 & 0.7111 & 0.7116 & 0.7120 \\
\hline
\end{tabular}

adaptive normalization which is additionally employed by NSGA-III and $\theta$-DEA. It must be understood that speed of an algorithm per iteration and convergence speed are different. In this regard, the performance of NSGA-II, NSGA-III and $\theta$-DEA are practically same although the performance of NSGA-II based on the mean values of speed of convergence and minimal net dissatisfaction is slightly superior to the others.

\subsection{Summary of Population Movement}

Several indicators are introduced in [13] which summarizes the population movement as a collection of plots. These indicators are inspired from radial plot visualisation method [6]. The indicators used for this work are plotted in Fig. 5 for three days in different groups and are summarized as follows:

1. Convergence: It is the fraction of reference lines which has shown improvements [13]. DEMO has a spiky plot (Fig. 5a, 5e, 5i) which indicates lack of 
convergence uniformly across the distributed set of reference lines. On the other hand, NSGA-II, NSGA-III and $\theta$-DEA has promptly converged to its approximate $P F$.

2. Diversity: It is the average degree of deviation of the spread of candidates across the reference lines from an ideal uniform spread of candidates [13]. DEMO has poor divergence than NSGA-II, NSGA-III and $\theta$-DEA (Fig. 5b, $5 \mathrm{f}, 5 \mathrm{j})$.

3. Innermost Radius: It is minimum radius (distance from origin) of a candidate across all reference lines, indicating convergence. Better convergence of NSGA-II, NSGA-III and $\theta$-DEA than DEMO is supported by Fig. $5 \mathrm{c}, 5 \mathrm{~g}$, $5 \mathrm{k}$. It can also be noted that during summer (Group 10, July 01, Fig. 5k), the achieved optima is much higher than other cases.

4. Inner Band: It is the difference between maximum and minimum inner radius, each defined over all the reference lines. Unlike the others, DEMO has convergence based ranking which helps it to achieve a close to zero inner band (Fig. 5d, 5h, 5l) indicating that all solutions have reached the same radius. NSGA-II, NSGA-III and $\theta$-DEA have higher inner bands showing that these algorithms have higher tendencies to harbor outliers.

\section{Conclusion and Future Scope}

The main objective of this work is to explore the most suited contemporary multi-objective optimization algorithms (DEMO, NSGA-II, NSGA-III and $\theta$ DEA) for determining the Pareto-optimal set of schedules for opening and closing of doors and windows such that a compromise between minimal thermal and $\mathrm{CO}_{2}$ based air quality dissatisfaction is attained.

Performance analysis is performed to determine the ability of the algorithms to attain minima along each objective, the ability of the algorithm to generate more alternatives for the end-user and the convergence speed of the algorithms. The results show that NSGA-II has superior tendency to outperform the other algorithms, however, the performance of NSGA-III and $\theta$-DEA does not lie far behind. In most of the cases, DEMO has not resulted in solutions which are as good as the solutions generated by the other algorithms. Specific characteristics of each of the algorithms responsible for the performance have been highlighted.

The experiment dealing with thermal and air quality dissatisfaction is a preliminary step towards a bigger goal where other criteria like humidity based air quality dissatisfaction, total energy usage, cost of consumption due to variable tariff, and many more come in to picture. Hence, the bi-objective problem will turn into a many-objective optimization problem where the characteristics of the problem identified in this work could be of great help. It should also be mentioned that the preference of an occupant towards each criteria and the preference of multiple occupants are essential while choosing an alternative schedule from the proposed set of solutions. Integrating such preferences into the framework are the other open areas of research for efficient building energy management. 


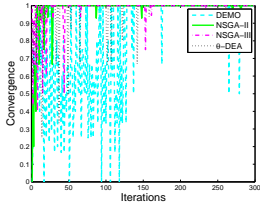

(a)

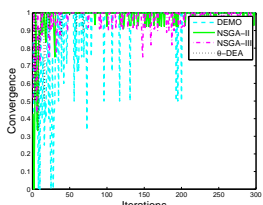

(e)

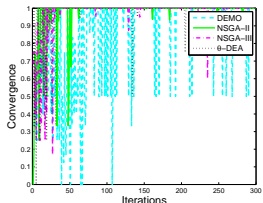

(i)

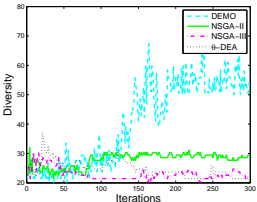

(b)

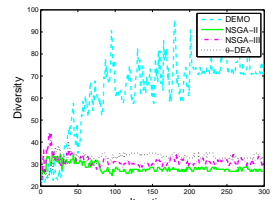

(f)

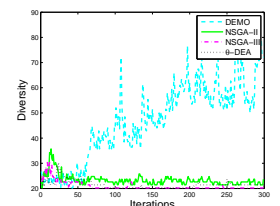

(j)

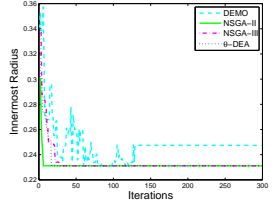

(c)

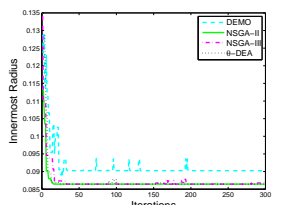

(g)

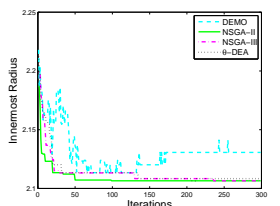

(k)

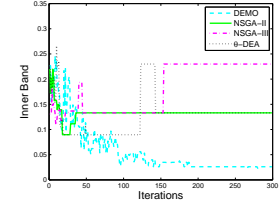

(d)

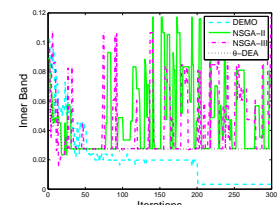

(h)

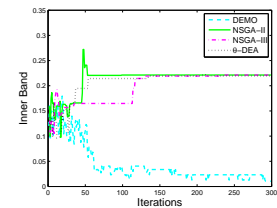

(I)

Fig. 5. Comparison of Population Movement across Iterations Representing Optimization based on Data Collected on Different Days: (a-d) Group 1 - April 08, (e-h) Group 6 - May 28, (i-l) Group 10 - July 01

\section{Acknowledgment}

This study is supported by the BiDEE project (DST-INRIA/ 2015-02/ BIDEE/ 0978) of Indo-French Centre for the Promotion of Advanced Research (CEFIPRA - IFCPAR) and by the INVOLVED ANR-14-CE22-0020-01 project [11] of the French National Research Agency.

\section{References}

1. Alyafi, A.A., Pal, M., Ploix, S., Reignier, P., Bandyopadhyay, S.: Differential explanations for energy management in buildings. In: IEEE Technically Sponsored Computing Conference. pp. 1-10 (Jul 2017)

2. Amayri, M., Arora, A., Ploix, S., Bandhyopadyay, S., Ngo, Q.D., Badarla, V.R.: Estimating occupancy in heterogeneous sensor environment. Energy and Buildings 129, 46-58 (2016)

3. Amayri, M., Ploix, S., Bandyopadhyay, S.: Estimating occupancy in an office setting. In: Sustainable Human-Building Ecosystems. pp. 72-80 (2015) 
4. Deb, K., Agrawal, S., Pratap, A., Meyarivan, T.: A fast elitist non-dominated sorting genetic algorithm for multi-objective optimization: Nsga-ii. Lecture notes in computer science 1917, 849-858 (2000)

5. Deb, K., Jain, H.: An evolutionary many-objective optimization algorithm using reference-point-based nondominated sorting approach, part i: solving problems with box constraints. Evolutionary Computation, IEEE Transactions on 18(4), 577-601 (2014)

6. He, Z., Yen, G.G.: Visualization and performance metric in many-objective optimization. IEEE Transactions on Evolutionary Computation 20(3), 386-402 (2016)

7. Ishibuchi, H., Tsukamoto, N., Nojima, Y.: Evolutionary many-objective optimization: A short review. In: IEEE congress on evolutionary computation. pp. 2419 2426 (2008)

8. Klein, L., Kwak, J.y., Kavulya, G., Jazizadeh, F., Becerik-Gerber, B., Varakantham, P., Tambe, M.: Coordinating occupant behavior for building energy and comfort management using multi-agent systems. Automation in construction 22, $525-536(2012)$

9. Masoso, O., Grobler, L.J.: The dark side of occupants behaviour on building energy use. Energy and buildings 42(2), 173-177 (2010)

10. Pal, M., Alzouhri Alyafi, A., Ploix, S., Reignier, P., Bandyopadhyay, S.: Enhancing Comfort of Occupants in Energy Buildings. Springer Nature Singapore (2016)

11. de la recherche, A.A.N.: Involved project (2015), http://www. agence-nationalerecherche.fr/?Projet=ANR-14-CE22-0020

12. Robič, T., Filipič, B.: Demo: Differential evolution for multiobjective optimization. In: Evolutionary multi-criterion optimization. pp. 520-533. Springer (2005)

13. Sengupta, R., Pal, M., Saha, S., Bandyopadhyay, S.: Population dynamics indicators for evolutionary many-objective optimization. In: Progress in Intelligent Computing Techniques: Theory, Practice, and Applications, pp. 1-10. Springer (2017)

14. Yuan, Y., Xu, H., Wang, B., Yao, X.: A new dominance relation-based evolutionary algorithm for many-objective optimization. IEEE Trans. Evolutionary Computation 20(1), 16-37 (2016), http://dx.doi.org/10.1109/TEVC.2015.2420112 